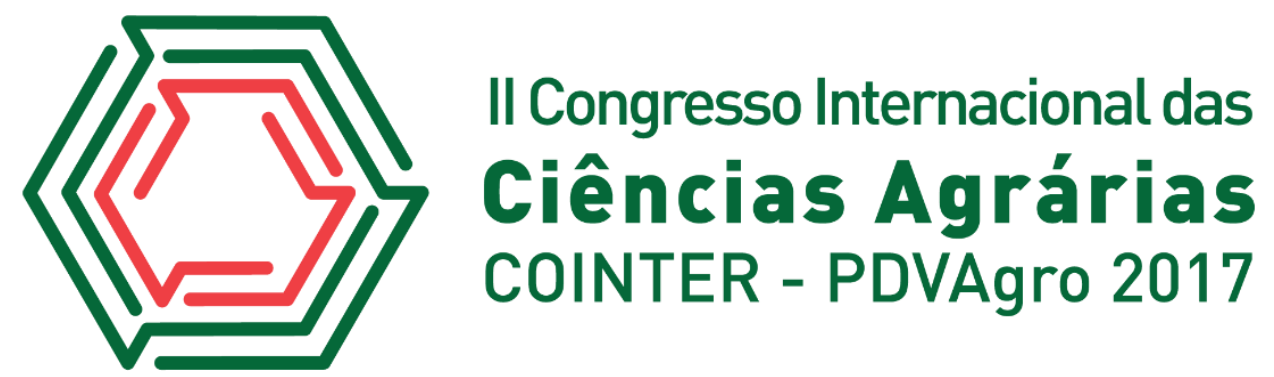

\title{
UTILIZAÇÃO DE TANINOS VEGETAIS COMO PRODUTO FLORESTAL NÃO MADEIREIRO NO NORDESTE DO BRASIL
}

\author{
João Paulo Silva Gomes ${ }^{1}$; Jaltiery Bezerra de Sousa ${ }^{2}$; Márcia Gabrielle de Almeida \\ Cardoso $^{3}$; Anderson Aurelio de Azevêdo Carnaval ${ }^{4}$; Tatiane Kelly Barbosa de Azevedo ${ }^{5}$
}

\section{Introdução}

A região nordeste do Brasil equivalente a $18 \%$ do território nacional e é a que detêm o maior número de estados (Alagoas, Bahia, Ceará, Maranhão, Paraíba, Piauí, Pernambuco, Rio Grande do Norte e Sergipe), e tem o maior número populacional em comparação com as demais regiões brasileiras, com características edafoclimáticas semiáridas, constituindo o bioma Caatinga (PANBRASIL, 2005; SILVA JÚNIOR \& SAMPAIO, 2011). A costa litorânea do nordeste tem como cobertura vegetal original a Mata Atlântica que se estende da Bahia até o Rio Grande do Norte. No entanto, o Bioma Caatinga tem a maior predominância na região, sendo apenas parte do Maranhão incluso no Bioma Amazônico (IBGE, 2013). Oriundos da diversidade ecossistêmica, os produtos florestais não madeireiros (PFNM) desempenham um papel importante no contexto socioeconômico da região Nordeste. Assim, estes produtos atuam na geração de emprego e renda, em especial para aquelas populações com escassas oportunidades produtivas (PAREYN, 2010).

$\mathrm{Na}$ Caatinga foram catalogadas 72 espécies vegetais utilizadas como PFNM, destas, 18 sofrem uso intensivo pelas populações locais (AGUIAR et al., 2014). Aproximadamente 1.177 empreendimentos de produtos florestais não madeireiros foram registrados pela Secretaria Nacional de Economia Solidária no ano 2005, no Nordeste do Brasil (PAREYN, 2010). Alguns autores denominam PFNMs como produtos de origem vegetal e animal e podem ser obtidos dos recursos naturais, bem como serviços sociais e ambientais, como reservas extrativistas, sequestro de carbono, conservação genética e outros produtos de origem florestal, dentre eles temos os taninos vegetais. (ELIAS e SANTOS, 2016). Os taninos vegetais caracterizam importância efetiva no setor florestal não madeireiro, podendo ser encontrado em várias partes da planta como: Flores, folhas, galhos,

\footnotetext{
${ }^{1}$ Engenharia Florestal, Universidade Federal do Rio Grande do Norte, jpgoms@hotmail.com

${ }^{2}$ Ciências Florestais, Universidade Federal do Rio Grande do Norte, jaltierytecseg@gmail.com

${ }^{3}$ Engenharia Florestal, Universidade Federal do Rio Grande do Norte, marcia.gabrielle@gmail.com

${ }^{4}$ Engenharia Florestal, Universidade Federal do Rio Grande do Norte, carnaval552@ufrn.edu.br

${ }^{5}$ Docente, Universidade Federal do Rio Grande do Norte, tatianekellyengenheira@hotmail.com
} 
raízes, frutos, sementes, e casca de diversas espécies florestais (PAES et al., 2010). Sendo utilizado para diversos fins, como exemplo: Adesivos para colagem de madeira, pela indústria petrolífera na perfuração de poços de petróleo e na produção de resinas e dispersante para controle de viscosidade na perfuração, tratamento de efluentes, curtimento de couro entre outras aplicabilidades. (TRUGILHO et al., 1997.; SILVA, 1999.; LELIS et al. 2001.; BATTESTIN et al. 2004.;PAES et al., 2006).

Com isso, pesquisas e informações tanto estatísticas quanto qualitativas que venham a compor o banco de informações dessa atividade é de extrema importância no cenário nacional (SANTOS et al., 2003; PAREYN, 2010). Baseado nisto, este trabalho teve como objetivo, levantar dados dos taninos vegetais como PFNM no Nordeste Brasileiro.

\section{Revisão bibliográfica}

Os taninos podem ser encontrados em várias partes da árvore, como na madeira, cascas, frutos, como também nas sementes (PAES et al., 2010), mas, em geral são retirados da madeira ou da casca (GONÇALVES e LELIS, 2001). Frequentemente, os taninos encontrados na madeira se diferenciam dos encontrados na casca, nas folhas e nos frutos (MORI et al., 2003) que desempenha um papel fundamental na economia da região Nordeste como produto florestal não madeireiro, apresentando um maior valor de toneladas produzidas (IBGE, 2015).

No Brasil, são várias as espécies que produzem taninos. Entre elas temos a acácia-negra (Acacia mearnsii de Willd) que é cultivada no estado do Rio Grande do Sul, (TANAC S.A. et al., 2009), o Eucalyptus astringens, o mangue-vermelho (Rhizophora candelaria) e o mangue-branco (Rhizophora mangle) que possuem de 20 a 30\% de tanino em suas cascas (HASLAM et al., 1966), o Angico vermelho (Anadenanthera colubrina (Vell.) Brenan), cujo foram pesquisadas todas as partes do vegetal (PAES et al., 2006), a jurema-preta (Mimosa tenuiflora (Willd.) Poir.) que possui um alto valor para a produção de taninos presente na casca (PAES et al., 2006) e a castanhola (Terminalia catappa, L.) que também apresenta quantidade satisfatória de tanino em sua casca para a produção comercial (SANTANA et al., 2009).

De acordo com Meunier e Ferreira (2015) o uso de tanantes vegetais na região Nordeste do Brasil é uma prática tradicional, adotada para preparação do couro usado na confecção de roupas tipicamente usadas pelos vaqueiros. Nesta região a espécie mais utilizada para a produção de tanino que possui como principal destinação o curtimento de couro, é o angico-vermelho (A. colubrina (Vell.) Brenan.) (PAES et al., 2006). Sendo que o uso dessa espécie já encontra-se ameaçada de 
extinção, por não possuir um manejo adequado e políticas que viabilizem o seu uso.

O segmento industrial que utiliza matéria prima proveniente dos taninos vegetais ocupa papel de destaque no setor de tanantes (LELIS et al. 2001). Sendo por tanto necessária, uma política de reflorestamento e manejo que vise à reposição das árvores exploradas para evitar o esgotamento a espécie florestal (PAES et al., 2006a). A jurema-preta (M. tenuiflora) é uma espécie que vem apresentando eficiência na produção de taninos, semelhante ao do angico-vermelho, e se trata de uma espécie de crescimento rápido, ocorrendo praticamente em quase todo território do Nordeste Brasileiro, atualmente é utilizada principalmente na produção de lenha (SANTOS, 2013) e carvão vegetal, e tem evidenciado elevado teor de tanino e eficiência não só para curtimento de pele, como também para outras utilizações como adesivo de madeira (AZEVEDO et al., 2015).

Na Figura 1 encontram-se os valores produzidos de 2006 a 2016 de tanantes dos Estados do Nordeste. Nota-se que a maior produção entre os Estados nordestinos foi o da Bahia.

Figura 1: Mapa de produção dos estados do nordeste brasileiro na produção (em toneladas) do grupo de tanantes no período entre 2006 - 2016. Dados do IBGE, Fonte: Própria.

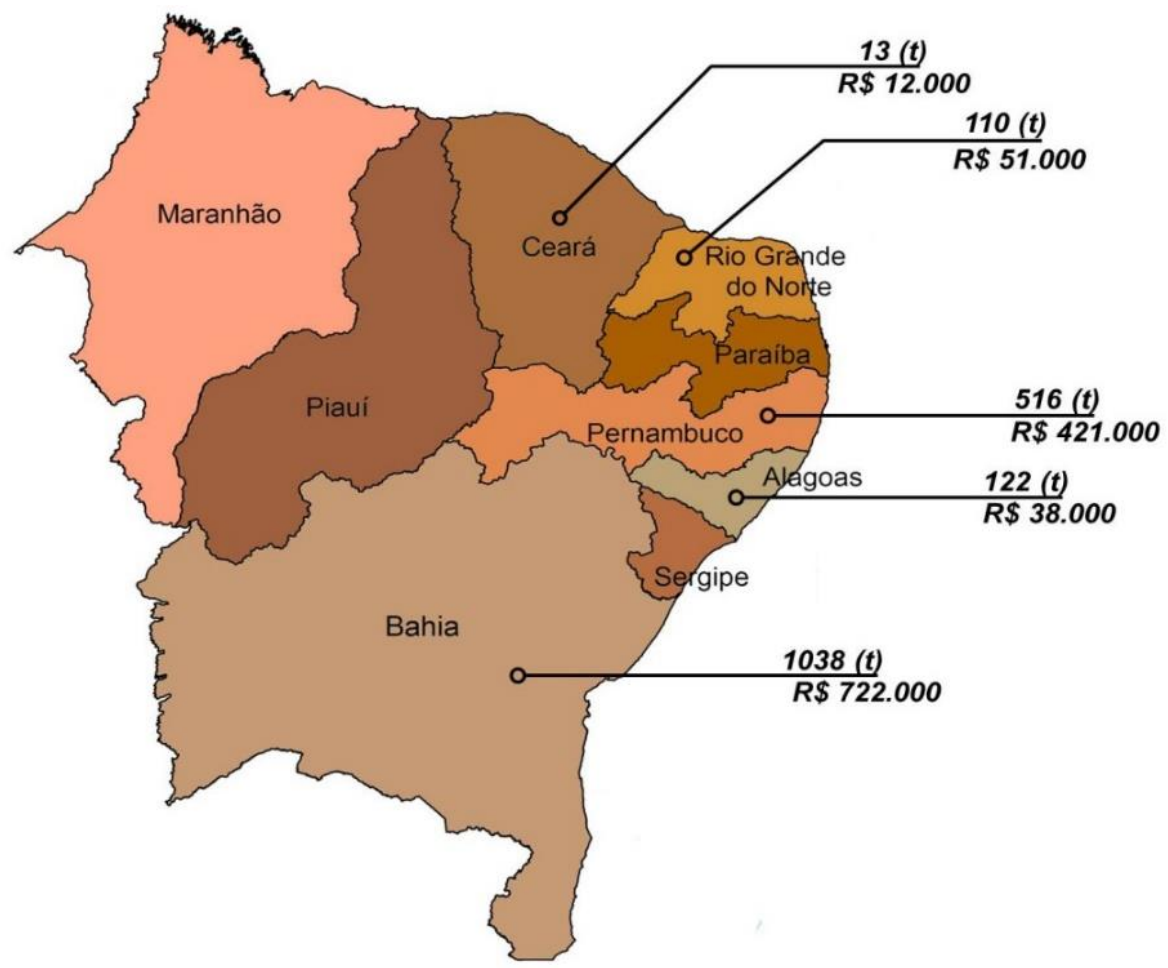

A principal fonte desses tanantes são as cascas do Angico e do Barbatimão, além de outras espécies. Todos os demais estados do nordeste também utilizam taninos vegetais, porém não são quantificados nas pesquisas realizadas pelo IBGE, assim como em nível nacional, a região Sul do País, que é a maior produtora de tanantes, não é quantificada devido a sua produção serem em 
grandes proporções, resultando em um evidente contraste com as demais regiões do Brasil.

\section{Metodologia}

Os dados foram obtidos por meio de levantamento bibliográficos e pesquisas em sites especializados. Com isso, foi apresentada a utilização de taninos vegetais como PFNM na região Nordeste do Brasil.

\section{Conclusões}

A região Nordeste é uma das principais produtoras de taninos vegetais, sendo sua principal utilização os taninos do angico vermelho para curtimento de pele, o que impulsiona a economia do país.

\section{Referências}

AZEVÊDO, T. K. B.; PAES, J. B.; CALEGARI, L.; NASCIMENTO, J. W. B. Qualidade dos taninos de jurema-preta (mimosa tenuiflora) para a produção de adesivo tanino formaldeído. Ciência Florestal, v. 25, n. 2, p. 507-514. 2015.

AGUIAR, G.P.; ROCHA, J.D.S.; SANTOS, A.J.; SILVA, J.C.G.L.; HOEFLICH, V.A.;COMPORTAMENTO DO MERCADO DOS PRINCIPAIS PRODUTOS FLORESTAIS NÃO-MADEIREIROS DA REGIÃO NORDESTE DO BRASIL. ENCICLOPÉDIA BIOSFERA, Centro Científico Conhecer - Goiânia, v.10, n.18; p. 2014.

ELIAS, G.A.; SANTOS, R.; PRODUTOS FLORESTAIS NÃO MADEIREIROS E VALOR POTENCIAL DE EXPLORAÇÃO SUSTENTÁVEL DA FLORESTA ATLÂNTICA NO SUL DE SANTA CATARINA. Ciência Florestal, Santa Maria, v. 26, n. 1, p. 249-262. 2016.

GONÇALVES, C. A.; LELIS, R.C.C. Teores de taninos na casca e na madeira de cinco leguminosas arbóreas. Floresta e Ambiente, Seropédica, v. 8, n. 1, p. 167-173, 2001.

HASLAM, E. Chemistry of vegetable tannins. New York: Academic Press, 177p. 1966.

IBGE | Portal do IBGE. https://www.ibge.gov.br. Acesso em : 25/09/2017

LELIS, C. C. R.; GONÇALVES, A de C. Teores de taninos da casca da madeira de cinco leguminosas arbóreas. Floresta e Ambiente. v. 8, n.1, p.167-173, 2001.

BATTESTIN, V.; MATSUDA, L. K.; MACEDO, G. A. Fontes e aplicações de taninos e Tanases em alimentos. Alimentos e Nutrição, Araraquara, v.15, n.1, p.63-72, 2004.

MEUNIER, I.M.J.; FERREIRA, R.L.C.; USO DE ESPECIES PRODUTORAS DE TANINOS PARA CURTIMENTO DE PELES NO NORDESTE DO BRASIL. Biodiversidade - V.14, N1, p. 98. 2015. 
MINISTÉRIO DO MEIO AMBIENTE. http://www.mma.gov.br. Acesso em: 26/09/2017.

MORI, F. A. et al. Influência do Sulfito e Hidróxido de Sódio na quantificação em taninos da casca de barbatimão (Stryphnodendron Adstringens). Floresta e Ambiente, Rio de Janeiro, v. 10, n. 1, p.86-92, jul. 2003.

MOUSINHO, N.; GOMES, J.P.S.; SOUZA, A.N.; UCELLAFILHO, J.G.M.; SOUSA, B.R.; CARNAVAL, A.A.; AZEVÊDO, T.K.B.; ESPÉCIES FLORESTAIS POTENCIALMENTE PRODUTORAS DE TANINOS: UMA REVISÃO BIBLIOGRÁFICA. III CBCTEM. Anais. 2017.

PAES, J. B.; DINIZ, C. E. F.; MARINHO, I. V.; LIMA, C. R. de. Avaliação do potencial tanífero de seis espécies florestais de ocorrência no Semi-Árido brasileiro. Revista Cerne, v.12, p.232-238, 2006.

PAES, J. B. et al. Substâncias tânicas presente em várias partes da árvore angico-vermelho (Anadenanthera colubrina (Vell.) Brenan. var. cebil (Gris.) Alts.). Scientia Forestalis, Piracicaba, v. 38, n. 87, p. $441-447,2010$.

PAREYN, F.G.C. Os recursos florestais nativos e a sua gestão no Estado de Pernambuco - o papel do manejo florestal sustentável. p. 99-115. In. Uso Sustentável e Conservação dos Recursos Florestais da Caatinga, Gariglio, M. A. et al., organizadores. Brasília: Serviço Florestal Brasileiro, 368p. 2010.

SANTOS, R.C. et al. Potencial energético da madeira de espécies oriundas de plano de manejo florestal no Estado do Rio Grande do Norte. Ciência Florestal, [s.l.], v. 23, n. 2, p.1192-1197, 28 jun. 2013.

SANTOS, A. J.; HILDEBRAND, E.; PACHECO, C. H. P.; PIRES, P. T. L.; ROCHADELLI, R. Produtos Não Madeireiros: Conceituação, classificação, valoração e mercados. Revista Floresta, Curitiba-PR, v. 33, n. 2, p. 215-224, 2003.

SILVA JÚNIOR, L. H.; SAMPAIO, Y. Pobreza rural Nordestina: o que há de Novo no Início deste Novo século? VII Encontro de Economia Baiana. Anais, Salvador, BA, setembro 2011.

SILVA, T. S. S. Estudo de tratabilidade físico-química com uso de taninos vegetais em água de abastecimento e de esgoto. 1999. 87p. Dissertação (Mestrado em Saúde Pública) - Escola Nacional de Saúde Pública - Fundação Oswaldo Cruz, São Paulo, 1999

TANAC, Manual prático para uso em estações de tratamento de água de abastecimento. Montenegro -RS, 2009.

TRUGILHO, P. F. et al. Avaliação do conteúdo em taninos condensados de algumas espécies típicas do cerrado mineiro. Cerne: Lavras, v.3, n.1, p.1-13, 1997. 